Gut and Liver, Vol. 11, No. 4, July 2017, pp. 551-558

\title{
Simeprevir-Based Triple Therapy with Reduced Doses of Pegylated Interferon $\alpha-2 a$ Plus Ribavirin for Interferon Ineligible Patients with Genotype 1b Hepatitis C Virus
}

\author{
Hideyuki Tamai ${ }^{1}$, Yoshiyuki Ida ${ }^{1}$, Akira Kawashima ${ }^{2}$, Naoki Shingaki ${ }^{1}$, Ryo Shimizu ${ }^{1}$, Kosaku Moribata ${ }^{1}$, Tetsushi Nasu ${ }^{2}$, \\ Takao Maekita $^{1}$, Mikitaka Iguchi ${ }^{1}$, Jun Kato ${ }^{1}$, Taisei Nakao ${ }^{2}$, and Masayuki Kitano ${ }^{1}$ \\ ${ }^{1}$ Second Department of Internal Medicine, Wakayama Medical University, and ${ }^{2}$ Department of Internal Medicine, Naga Municipal Hospital, \\ Wakayama, Japan
}

\begin{abstract}
Background/Aims: The present study aimed to evaluate the safety and efficacy of simeprevir-based triple therapy with reduced doses of pegylated interferon (PEG-IFN) and ribavirin for interferon (IFN) ineligible patients, such as elderly and/or cirrhotic patients, and to elucidate the factors contributing to a sustained virologic response (SVR). Methods: One hundred IFN ineligible patients infected with genotype $1 \mathrm{~b}$ hepatitis $\mathrm{C}$ virus (HCV) were treated. Simeprevir (100 mg) was given orally together with reduced doses of PEG-IFN- $\alpha 2 a(90 \mu \mathrm{g})$, and ribavirin (200 $\mathrm{mg}$ less than the recommended dose). Results: The patients' median age was 70 years, and 70 patients were cirrhotic. Three patients (3\%) discontinued treatment due to adverse events. The SVR rate was $64 \%$. Factors that significantly contributed to the SVR included the $\gamma$-glutamyl transferase and $\alpha$-fetoprotein levels, interleukin28B (IL28B) polymorphism status, and the level and reduction of HCV RNA at weeks 2 and 4. The multivariate analysis showed that the IL28B polymorphism status was the only independent factor that predicted the SVR, with a positive predictive value of $77 \%$. Conclusions: Simeprevir-based triple therapy with reduced doses of PEG-IFN and ribavirin was safe and effective for IFN ineligible patients infected with genotype 1b HCV. IL28B polymorphism status was a useful predictor of the SVR. (Gut Liver 2017;11:551-558)
\end{abstract}

Key Words: Hepacivirus; Pegylated interferon; Ribavirin; Simeprevir; Interleukin-28B

\section{INTRODUCTION}

The goal of antiviral therapy for hepatitis C virus (HCV) pa- tients is to prevent liver-related death. Therefore, elderly and/ or cirrhotic patients infected with HCV, who are at high risk of developing cirrhosis and/or hepatocellular carcinoma, ${ }^{1}$ have to be treated as soon as possible. ${ }^{2}$ The safety of treatment with recommended doses of pegylated interferon (PEG-IFN) and ribavirin for elderly and/or cirrhotic patients was problematic because of adverse effects. ${ }^{3,4}$ In 2011, reduced doses of PEG-IFN and ribavirin for cirrhotic patients were approved for clinical use under national medical insurance in Japan. ${ }^{2}$ Although the reduced dose regimens of PEG-IFN and ribavirin for cirrhotic patients infected with genotype-1 HCV were tolerable, the sustained viral response (SVR) rates were relatively lower $(11.3 \%$ to $37 \%)$ compared with those of noncirrhotic patients. ${ }^{5-9}$

In November 2011, the first-generation nonstructural 3/4A protease inhibitor, telaprevir, based triple therapy was approved in Japan. Although this treatment significantly improved SVR rates up to around 70\%, severe adverse reactions such as serious skin disorders, exacerbation of anemia, and renal dysfunction occurred frequently. ${ }^{10}$ Notably, in our previous study, even reduced dose of telaprevir-based triple therapy had limited safety and efficacy for elderly and/or cirrhotic patients. ${ }^{11}$ In November 2013, a new triple therapy using the second-generation nonstructural 3/4A protease inhibitor, simeprevir, became available for clinical use in Japan. In phase III trials of this therapy, serious adverse effects did not occur more frequently in the simeprevir group than in the group who did not receive simeprevir, and the addition of simeprevir to PEG-IFN and ribavirin significantly improved the SVR rate (74.7\% to $88.6 \%)$, and shortened the duration of treatment. ${ }^{12-14}$ However, in these trials, most patients were younger (the patient's median age was around 50 years), the proportion of cirrhotic patients was low,

Correspondence to: Hideyuki Tamai

Second Department of Internal Medicine, Wakayama Medical University, 811-1 Kimiidera, Wakayama 641-0012, Japan

Tel: +81-73-447-2300, Fax: +81-73-445-3616, E-mail: tamahide@wakayama-med.ac.jp

Received on October 26, 2016. Revised on December 10, 2016. Accepted on December 23, 2016. Published online May 17, 2017

pISSN 1976-2283 eISSN 2005-1212 https://doi.org/10.5009/gnl16525

@) This is an Open Access article distributed under the terms of the Creative Commons Attribution Non-Commercial License (http://creativecommons.org/licenses/by-nc/4.0) which permits unrestricted non-commercial use, distribution, and reproduction in any medium, provided the original work is properly cited. 
and cirrhotic patients were excluded in the Japanese phase III trial. $^{15}$

The present study aimed to evaluate the safety and efficacy of simeprevir-based triple therapy with reduced doses of PEG-IFN and ribavirin for IFN ineligible patients such as elderly and/or cirrhotic patients infected with genotype $1 \mathrm{~b} \mathrm{HCV}$, as well as to elucidate the factors contributing to SVR.

\section{MATERIALS AND METHODS}

\section{Patients}

This was a prospective cohort study of simeprevir-based triple therapy with reduced doses of PEG-IFN- $\alpha-2$ a plus ribavirin for IFN ineligible patients infected with genotype 1b HCV (University hospital medical information network trial ID: 000022491). A total of 100 IFN ineligible patients were enrolled from January 2014 to October 2014 in Wakayama Medical University Hospital and Naga Municipal Hospital. "Elderly" was defined as more than 65 years of age. Liver cirrhosis was diagnosed clinically by liver biopsy or imaging studies using the morphologic signs of cirrhosis from portal hypertension, such as portosystemic shunt or hypersplenism. IFN ineligible patients were defined as patients with any of the following: (1) age $\geq 65$ years; (2) white blood cell count $<2,000 / \mathrm{mm}^{3}$; (3) platelet count $<130,000 / \mathrm{mm}^{3}$; (4) Hb level <13 g/dL; (5) a comorbid disorder such as psychiatric disease, heart disease, cerebrovascular disease, thyroid disease, autoimmune disease, or uncontrolled diabetes; or (6) low body weight $(<40 \mathrm{~kg}$ ). Exclusion criteria were (1) pregnant women, women who may have been pregnant, lactating women, men whose partners were pregnant, or men whose partners hoped to become pregnant; (2) patients who used shosaikoto (a traditional Chinese medicine); (3) intractable heart disease; (4) renal failure with creatinine clearance $<50 \mathrm{~mL} / \mathrm{min}$; (5) patients with uncontrollable psychoneurotic disorders; (6) hemoglobin (Hb) levels < $10 \mathrm{~g} / \mathrm{dL}$; (7) platelet count $<50,000 / \mathrm{mm}^{3}$; (8) white blood cell count $<1,500 / \mathrm{mm}^{3}$ (or granulocyte count $<1,000$ / $\mathrm{mm}^{3}$ ); and (9) hepatic failure or cancer; (10) infection with human immunodeficiency virus and/or hepatitis B virus; (11) organ transplantation; and (12) pretreatment failure of telaprevir based triple therapy. All study protocols were approved by the ethics committees of the participating hospitals. Written informed consent was obtained from all patients included in the study.

\section{Treatment regimens}

Simeprevir (Sovriad ${ }^{\circledR}$; Janssen Pharmaceutical K.K., Tokyo, Japan), PEG-IFN- $\alpha-2$ a (Pegasys ${ }^{\circledR}$; Chugai Pharmaceutical Co., Ltd., Tokyo, Japan) and ribavirin (Copegus ${ }^{\circledR}$; Chugai Pharmaceutical Co., Ltd.) were used. PEG-IFN- $\alpha-2$ a at $90 \mu \mathrm{g}$ was administered subcutaneously once per week for 24 weeks; ribavirin was given orally for 24 weeks ( $800 \mathrm{mg} /$ day for patients weighing more than $80 \mathrm{~kg}, 600 \mathrm{mg} /$ day for patients weighing between 80 and $60 \mathrm{~kg}$, and $400 \mathrm{mg} /$ day for patients weighing less than $60 \mathrm{~kg}$ ); Simeprevir was given orally at a dose of 100 $\mathrm{mg}$ (the recommended dose in Japan) once per day for 12 weeks from the start of therapy.

PEG-IFN- $\alpha-2 \mathrm{a}$ was discontinued if the granulocyte count fell below $500 / \mathrm{mm}^{3}$ or the platelet count fell below $30,000 / \mathrm{mm}^{3}$, and ribavirin $200 \mathrm{mg}$ was reduced if the $\mathrm{Hb}$ fell below $10 \mathrm{~g} / \mathrm{dL}$, and if the $\mathrm{Hb}$ fell below $8.5 \mathrm{~g} / \mathrm{dL}$, the ribavirin was discontinued. If there was no improvement of cytopenia within 4 weeks, therapy was discontinued. Granulocyte colony-stimulating factor (G-CSF) could be used as supplementary treatment for granulocytopenia of less than $500 / \mathrm{mm}^{3}$.

\section{Laboratory tests}

For all patients, laboratory tests were performed before therapy began. The amount of HCV RNA was measured using quantitative reverse transcription polymerase chain reaction (RT-PCR, COBAS TaqMan PCR assay; Roche Diagnostics, Branchburg, NJ, USA). Determination of HCV genotype was performed as reported by Simmonds et al. ${ }^{16}$ The amount of HCV-RNA (AccuGene ${ }^{\circledR}$ m-HCV; Abbott Japan, Tokyo, Japan) and HCV core antigen levels (Architect ${ }^{\circledR} \mathrm{HCV}$; Abbott Japan) were measured simultaneously at three stages: the day of therapy initiation, and at weeks 1 and 2. Serum levels of hyaluronic acid and type IV collagen 7S were measured for assessment of liver fibrosis on the day of therapy initiation. Mutations in the IFN sensitivity-determining region (ISDR) ${ }^{17}$ and amino acid substitutions in HCV core region 70 and $91^{18}$ were also measured on the day of therapy initiation. ISDR was defined as wild type if no mutations were identified, and all others were defined as mutant type. At core 70, arginine was defined as the wild type, and glutamine or histidine as mutant types. At core 91, leucine was defined as the wild type, and methionine as the mutant type. During therapy, the levels of HCV RNA (COBAS TaqMan PCR assay; Roche Diagnostics) were checked, and biochemical analyses including blood counts, serum alanine aminotransferase, and aspartate aminotransferase, $\gamma$-glutamyl transferase $(\gamma$-GT) and $\alpha$-fetoprotein (AFP) levels were performed every 4 weeks up to 24 weeks after the end of therapy. After treatment, the SNP of IL28B (rs8099917) that was reported as a pretreatment predictor for the efficacy of PEG-IFN plus ribavirin therapy in Japanese patients ${ }^{19}$ was additionally evaluated, after obtaining written informed consent for genome analysis from each patient. Homozygosity for the major allele (T/ T) was defined as the IL28B major type, and heterozygosity (T/G) or homozygosity for the minor allele $(\mathrm{G} / \mathrm{G})$ was defined as the IL28B minor type.

\section{Assessment of effectiveness}

During IFN therapy, rapid virologic response (RVR) was defined as an undetectable virus by quantitative RT-PCR (COBAS 
TaqMan PCR assay; Roche Diagnostics) at week 4 after therapy initiation. SVR was defined as follows: HCV RNA measured using the TaqMan PCR assay was negative at the end of therapy and remained negative for 24 weeks after the end of therapy. No response was defined as detectable HCV RNA at week 24 from treatment initiation or at the end of treatment. Relapse was defined as negative at the end of therapy but positive 24 weeks after the end of therapy.

\section{Assessment of safety and tolerability}

Patients were assessed for safety and tolerability during treatment by their attending physicians, who monitored adverse events and laboratory parameters, such as blood cell counts, every week up to week 8 , and monthly thereafter. The incidence of and reasons for therapy discontinuation due to adverse effects were analyzed. Adherence to simeprevir, PEG-IFN- $\alpha-2 \mathrm{a}$ and ribavirin were also assessed separately.

\section{Statistical analysis}

Therapeutic effectiveness was evaluated using an intentionto-treat (ITT) analysis. Predictive factors for SVR were analyzed using an ITT analysis that included patients who had discontinued therapy due to adverse events. The Mann-Whitney U test was used to analyze continuous variables. Fisher exact test or the chi-square test was used to analyze categorical variables. Multivariate analysis was performed using a logistic regression model with the stepwise method. The criterion for selecting factors for multivariate analysis was $\mathrm{p}<0.05$. Optimal cutoff value for continuous variables of contributing factors to SVR was decided by the Youden Index method on the basis of the receiver operating characteristics curve. The SVR-predictability of significant SVR-contributing factors was evaluated by measuring the area under the curve (AUC). The sensitivity, specificity, positive predictive value (PPV), negative predictive value (NPV), and accuracy for SVR were calculated. Values of $p<0.05$ were considered statistically significant. SPSS statistical software version 21J for Windows (SPSS Inc., Tokyo, Japan) was used for data analyses.

\section{RESULTS}

\section{Patients' baseline characteristics}

Patients' baseline characteristics are summarized in Table 1. There were 72 elderly patients (72\%), 70 cirrhotic patients (70\%), 20 nonelderly and cirrhotic patients (20\%), 22 elderly and noncirrhotic patients (22\%), and 50 elderly and cirrhotic patients $(50 \%)$ in the present study.

\section{Safety and tolerability}

Three patients (3\%) discontinued the therapy due to adverse events. Reasons for discontinuation were severe fatigue in one patient, facial palsy in one patient, and hepatic failure with ascites in one patient. The mean \% adherences (mean \pm standard deviation) to PEG-IFN- $\alpha-2 \mathrm{a}$, ribavirin and, simeprevir among the 100 enrolled patients were $99.6 \% \pm 12.4 \%, 94.5 \% \pm 14.2 \%$, and $98.8 \% \pm 6.5 \%$, respectively. Interruption of any drug was required in 14 patients (14\%) because of adverse effects including eight with severe anemia, two with neutropenia, one with hyperbilirubinemia, one with hyperthyroidism, one with acute pyelonephritis and one with pharyngitis. Regular administration of G-CSF was required in two patients. Dose reduction or interruption of ribavirin was required in 29 patients (29\%).

\section{Treatment response}

The HCV-RNA level re-elevated at week 2 in one patient, and at week 4 in three patients. Two patients re-elevated at 4 weeks after the completion of simeprevir. RVR was achieved

Table 1. Baseline Characteristics of the Study Population ( $n=100)$

\begin{tabular}{|c|c|}
\hline Factor & Value \\
\hline Age, yr & $70(43-86)$ \\
\hline Sex (male/female) & $58 / 42$ \\
\hline Height, cm & $159.5(140.0-177.3)$ \\
\hline Weight, kg & $59.1(37.0-95.0)$ \\
\hline BMI, $\mathrm{kg} / \mathrm{m}^{2}$ & $23.1(16.5-35.6)$ \\
\hline Baseline HCV-RNA $\left(\right.$ TaqMan $\left.^{\circledR}\right)$, log IU/mL & $6.7(4.3-7.6)$ \\
\hline $\begin{array}{l}\text { Response to prior PEG-IFN and ribavirin } \\
\text { (NR/relapse/naïve) }\end{array}$ & $23 / 25 / 52$ \\
\hline Cirrhosis & 70 \\
\hline History of HCC treatment & 30 \\
\hline IL28B, rs8099917 (TT/GT/GG) & $75 / 23 / 2$ \\
\hline ISDR (wild/mutant) & $90 / 10$ \\
\hline Core 70 (wild/mutant) & $54 / 46$ \\
\hline Core 91 (wild/mutant) & $58 / 42$ \\
\hline $\mathrm{WBC}, / \mathrm{mm}^{3}$ & $4,295(1,610-8,940)$ \\
\hline $\mathrm{Hb}, \mathrm{g} / \mathrm{dL}$ & $13.3(10.6-16.8)$ \\
\hline Platelet, $/ \mathrm{mm}^{3}$ & $12.4(5.0-30.2)$ \\
\hline AST, IU/L & $55(20-209)$ \\
\hline ALT, IU/L & $51(14-230)$ \\
\hline$\gamma-\mathrm{GT}, \mathrm{IU} / \mathrm{L}$ & $33(11-387)$ \\
\hline Type IV collagen 7S, ng/mL & $5.9(2.9-27.9 .3)$ \\
\hline Hyaluronic acid, ng/mL & $183(12-4,795)$ \\
\hline AFP, ng/mL & $6.9(1.0-140.3)$ \\
\hline
\end{tabular}

Data are presented median (range) or number.

BMI, body mass index; HCV, hepatitis C virus; PEG-IFN, pegylated interferon; NR, no response; HCC, hepatocellular carcinoma; IL, interleukin; ISDR, interferon sensitivity determining region; WBC, white blood cell; $\mathrm{Hb}$, hemoglobin; AST, aspartate aminotransferase; ALT, alanine aminotransferase; $\gamma$-GT, $\gamma$-glutamyl transferase; AFP, $\alpha$-fetoprotein. 
in 69 patients (69\%). SVR was achieved in 64 patients (64\%), relapse occurred in 29 patients (29\%), and no response was seen in five patients (5\%). The SVR rate of RVR patients was 77\% (53/69). SVR rates of treatment naïve patients, relapsers, and nonresponders to prior PEG-IFN and ribavirin therapy were 67\% (35/52), 72\% (18/25), 48\% (11/23), respectively. SVR rates of elderly, cirrhotic, and both elderly and cirrhotic patients were 64\% (46/72), 63\% (44/70), 62\% (31/50), respectively.

\section{Contributing factors for SVR and prediction of SVR}

Comparison of pretreatment factors between the SVR and non-SVR group is summarized in Table 2. Significant differences are noted for IL28B polymorphism, $\gamma$-GT level, and AFP level. However, no significant differences were seen for age, sex, body weight, baseline HCV-RNA level, cirrhosis, response to prior PEG-IFN and ribavirin therapy, ISDR, core amino acid substitution, and fibrosis markers. Comparison of on-treatment factors between the SVR and non-SVR groups is summarized in Table 3. Significant differences were noted for the HCV-RNA levels and reductions at week 2 and 4, and RVR. However, no significant differences were seen for the response of $\mathrm{HCV}$ core $\mathrm{Ag}$ within 2 weeks, and drug adherences. Results of the multivariate analysis of significant factors contributing to SVR are shown in Table 4. IL28B polymorphism was the only independent factor. The AUCs according to significant SVR-factors are summarized in Table 5. For all significant factors, the highest AUC value was the reduction of HCV-RNA at week 4. The sensitivity, specificity, PPV, NPV, and accuracy for predicting SVR using IL28B major and reduction of HCV-RNA at week 4 (cut off value, $>5.75 \mathrm{log}$ $\mathrm{IU} / \mathrm{mL}$ ) are shown in Table 6. Both the SVR-predictabilities were equivalent.

\section{DISCUSSION}

This is the first report of simeprevir based triple therapy with reduced doses PEG-IFN- $\alpha-2$ a plus ribavirin for IFN ineligible

Table 2. Comparison of Pretreatment Factors between Patients with and without a Sustained Virologic Response

\begin{tabular}{|c|c|c|c|}
\hline Factor & SVR $(n=64)$ & Non-SVR $(n=36)$ & $\mathrm{p}$-value \\
\hline Age, yr & $70(47-84)$ & $69(43-86)$ & 0.568 \\
\hline Sex (male/female) & $34 / 30(53 / 47)$ & $24 / 12(67 / 33)$ & 0.211 \\
\hline Height, cm & $158.1(140.0-177.3)$ & $160.6(144.0-173.1)$ & 0.322 \\
\hline Weight, kg & $57.9(37.0-77.4)$ & $60.4(42.4-95)$ & 0.088 \\
\hline BMI, $\mathrm{kg} / \mathrm{m}^{2}$ & $22.9(16.51-29.77)$ & $23.7(19.3-35.6)$ & 0.190 \\
\hline Baseline HCV-RNA (TaqMan ${ }^{\circledR}$ ), log IU/mL & $6.7(5.1-7.6)$ & $6.6(4.3-7.3)$ & 0.597 \\
\hline Baseline HCV-RNA (AccuGene ${ }^{\circledR}$ ), log IU/mL & $6.3(4.5-7.4)$ & $6.2(4.0-6.8)$ & 0.466 \\
\hline Baseline HCV core Ag, fmol/L & $5,934.8(137.2-34,571.1)$ & $5,600.0(37.79-20,000.0)$ & 0.340 \\
\hline No response to prior PEG-IFN and ribavirin & $11(17)$ & $12(33)$ & 0.084 \\
\hline Cirrhosis & $44(69)$ & $26(72)$ & 0.716 \\
\hline History of HCC treatment & $21(33)$ & $9(25)$ & 0.413 \\
\hline IL28B polymorphism (major/minor) & $58 / 6(91 / 9)$ & $17 / 19(47 / 53)$ & $<0.001$ \\
\hline ISDR (wild/mutant) & $57 / 7(90 / 10)$ & $33 / 3(92 / 8)$ & 1.000 \\
\hline Core 70 (wild/mutant) & $37 / 27(58 / 42)$ & $17 / 19(47 / 53)$ & 0.308 \\
\hline Core 91 (wild/mutant) & $39 / 25(61 / 39)$ & $19 / 17(53 / 47)$ & 0.427 \\
\hline WBC, $/ \mathrm{mm}^{3}$ & $4,240(1,610-8,760)$ & $4,355(1,870-8,940)$ & 0.643 \\
\hline $\mathrm{Hb}, \mathrm{g} / \mathrm{dL}$ & $13.2(11.1-16.1)$ & $13.4(10.6-16.8)$ & 0.659 \\
\hline Platelet, $/ \mathrm{mm}^{3}$ & $13.2(5.8-30.2)$ & $11.6(5.0-24.0)$ & 0.209 \\
\hline AST, IU/L & $56(20-170)$ & $54(20-209)$ & 0.951 \\
\hline ALT, IU/L & $51(17-176)$ & $49(14-230)$ & 0.782 \\
\hline$\gamma$-GT, IU/L & $30(11-387)$ & $40(13-233)$ & 0.016 \\
\hline Type IV collagen 7S, ng/mL & $5.8(2.9-15.2)$ & $6.4(3.2-27.9)$ & 0.385 \\
\hline Hyaluronic acid, ng/mL & $172(12-4,795)$ & $210(29-956)$ & 0.189 \\
\hline AFP, ng/mL & $6.3(1.0-140.3)$ & $10.0(1.8-136.1)$ & 0.017 \\
\hline
\end{tabular}

Data are presented as median (range) or number (\%).

SVR, sustained virologic response; BMI, body mass index; HCV, hepatitis C virus; Ag, antigen; PEG-IFN, pegylated interferon; HCC, hepatocellular carcinoma; IL, interleukin; ISDR, interferon sensitivity determining region; WBC, white blood cell; Hb, hemoglobin; AST, aspartate aminotransferase; ALT, alanine aminotransferase; $\gamma$-GT, $\gamma$-glutamyl transferase; AFP, $\alpha$-fetoprotein. 
Table 3. Comparison of On-Treatment Factors between Patients with and without a Sustained Virologic Response

\begin{tabular}{lccr}
\hline \multicolumn{1}{c}{ Factor } & SVR (n=64) & Non-SVR (n=36) & p-value \\
\hline HCV-RNA level at week 1, log IU/mL & $1.8(0.0-3.1)$ & $1.9(0.0-3.2)$ & 0.161 \\
HCV-RNA level at week 2, log IU/mL & $1.1(0.0-2.5)$ & $1.4(0.0-3.3)$ & 0.002 \\
HCV-RNA level at week 4, log IU/mL & $0.0(0.0-1.2)$ & $1.2(0.0-5.4)$ & $<(44)$ \\
RVR & $53(83)$ & $4.1(2.7-5.3)$ & $<.001$ \\
Reduction of HCV-RNA at week 1, log & $4.4(3.3-6.2)$ & $4.8(2.6-6.0)$ & 0.001 \\
Reduction of HCV-RNA at week 2, log & $5.2(3.7-6.2)$ & $5.5(1.2-7.3)$ & 0.002 \\
Reduction of HCV-RNA at week 4, log & $6.5(4.7-7.5)$ & $7.5(0.8-48.2)$ & $1.9(0.0-23.0)$ \\
HCV core Ag level at week 1, fmol/L & $5.0(0.0-83.1)$ & $5,590.9(36.9-19,998.7)$ & 0.677 \\
HCV core Ag level at week 2, fmol/L & $1.4(0.0-28.9)$ & $5,591.9(37.8-20,000.0)$ & 0.527 \\
Reduction of HCV core Ag at week 1 & $5,928.5(137.2-34,556.1)$ & $100(50-100)$ & 0.343 \\
Reduction of HCV core Ag at week 2 & $5,931.4(137.2-34,565.2)$ & $100(13-100)$ & 0.343 \\
Simeprevir adherence, \% & $100(92-100)$ & $100(22-100)$ & 0.655 \\
PEG-IFN adherence, \% & $100(46-100)$ & 0.944 \\
Ribavirin adherence, \% & $100(34-100)$ & 0.630 \\
\hline
\end{tabular}

Data are presented as median (range) or number (\%).

SVR, sustained virologic response; HCV, hepatitis C virus; RVR, rapid virologic response; Ag, antigen; PEG-IFN, pegylated interferon.

Table 4. Multivariate Analyses of Contributing Factors to a Sustained Virologic Response

\begin{tabular}{lccc}
\multicolumn{1}{c}{ Factor } & p-value & Odds ratio & $95 \%$ CI \\
\hline IL28B major & 0.005 & 6.162 & $1.741-21.810$ \\
AFP, ng/mL & 0.451 & 0.992 & $0.972-1.013$ \\
$\gamma$-GT, IU/L & 0.771 & 1.002 & $0.990-1.013$ \\
HCV-RNA level at week 2, log IU/mL & 0.634 & 1.453 & $0.312-6.769$ \\
HCV-RNA level at week 4, log IU/mL & 0.997 & 0.000 & $0.000-0.000$ \\
RVR & 0.997 & 0.000 & $0.000-0.000$ \\
Reduction of HCV-RNA at week 2, log & 0.707 & 1.383 & $0.255-7.491$ \\
Reduction of HCV-RNA at week 4, log & 0.936 & 0.945 & $0.238-3.751$ \\
\hline
\end{tabular}

CI, confidence interval; IL, interleukin; AFP, $\alpha$-fetoprotein; $\gamma$-GT, $\gamma$-glutamyl transferase; HCV, hepatitis C virus; RVR, rapid virologic response.

Table 5. Area under the Receiver Operating Characteristic Curve Based on Significant Factors That Contribute to a Sustained Virologic Response

\begin{tabular}{llcc}
\hline \multicolumn{1}{c}{ Factor } & AUC & p-value & $95 \%$ CI \\
\hline IL28B major & 0.717 & $<0.001$ & $0.604-0.830$ \\
AFP, ng/mL & 0.645 & 0.017 & $0.531-0.758$ \\
$\gamma$-GT, IU/L & 0.646 & 0.016 & $0.534-0.759$ \\
HCV-RNA at week 2, log IU/mL & 0.667 & 0.006 & $0.553-0.781$ \\
Reduction of HCV-RNA at week 2, log & 0.677 & 0.003 & $0.567-0.787$ \\
HCV-RNA at week 4, log IU/mL & 0.722 & $<0.001$ & $0.611-0.834$ \\
Reduction of HCV-RNA at week 4, log & 0.742 & $<0.001$ & $0.635-0.849$ \\
RVR & 0.692 & $<0.001$ & $0.579-0.805$ \\
\hline
\end{tabular}

AUC, area under the receiver operating characteristic curve; CI, confidence interval; IL, interleukin; AFP, $\alpha$-fetoprotein; $\gamma$-GT, $\gamma$-glutamyl transferase; $\mathrm{HCV}$, hepatitis $\mathrm{C}$ virus; RVR, rapid virologic response.

Table 6. Predictive Values of Interleukin 28B for a Sustained Virologic Response and Reduction of the Viral Load at Week 4

\begin{tabular}{lllllc}
\hline \multicolumn{1}{c}{ Significant predictive factor } & Sensitivity & Specificity & PPV & NPV & Accuracy \\
\hline IL28B major & $91(58 / 64)$ & $53(19 / 36)$ & $77(58 / 75)$ & $76(19 / 25)$ & $77(77 / 100)$ \\
Reduction of HCV-RNA at week $4(>5.75 \log \mathrm{IU} / \mathrm{mL})$ & $83(53 / 64)$ & $64(23 / 36)$ & $80(53 / 66)$ & $68(23 / 34)$ & $76(76 / 100)$ \\
\hline
\end{tabular}

Values are presented as \% (number/total number).

PPV, positive predict value; NPV, negative predict value; IL, interleukin; HCV, hepatitis C virus. 
patients mainly including elderly and/or cirrhotic patients. Regarding safety, the treatment discontinuation rate in the present study was lower (3\%) compared with that (14.5\%) in systemic review of interferon therapy for cirrhotic patients. ${ }^{4}$ In the Japanese Phase III trial of simeprevir-based triple therapy, the discontinuation rate in the simeprevir group was $4.9 \% .^{15}$ Therefore, it is conceivable that simeprevir-based triple therapy with reduced doses of PEG-IFN and ribavirin was well tolerable even for IFN ineligible patients such as elderly and/or cirrhotic patients. In the present study, however, 14\% interruption of any drugs, 29\% dose reduction or interruption of ribavirin was required. It has been reported that elderly or diabetic patients have a high risk of developing severe infection during interferon therapy..$^{20}$ Therefore, for elderly and/or cirrhotic patients, with particular attention to occurrence of serious adverse effects such as severe infection or hepatic failure, careful observation and adequate management of adverse effects would be needed even in reduced dose regimen.

The SVR rate in the present study was 64\%, and this was relatively low compared with those (85\% and 87\%) of postmarketing studies of simeprevir based triple therapy in Japan. ${ }^{21,22}$ However, most patients in these studies were not cirrhotic. Advanced liver fibrosis is an unfavorable factor contributing to SVR in IFN based therapy. In fact, the SVR rates of simeprevir group in the phase III QUEST-1 trial also became lower along with advancing liver fibrosis (METAVIR score F0-2, 83\%; F3, $78 \%$; F4, 58\%). ${ }^{13}$ On the other hand, Tahata et al..$^{22}$ reported that although PEG-IFN- $\alpha-2$ a dose was not a significant factor associated with SVR, ribavirin dose affected with SVR in patients. Therefore, the reason for the lower SVR rate in this study might be attributed to patients' characteristics such as advanced fibrosis and reduced ribavirin dose. However, the SVR rate is still roughly twice as high as those of reduced dose PEG-IFN and ribavirin regimen for cirrhotic patients infected with genotype-1 HCV in previous reports. ${ }^{5-9}$ Therefore, it is conceivable that even reduced dose regimen could increase the SVR rate. However, there was no control group in our study. Therefore, a randomized controlled trial is desirable to validate our results.

Some reports indicated that prior treatment response to PEGIFN and ribavirin based therapy significantly impacted on SVR of simeprevir based triple therapy. ${ }^{23-25}$ The SVR rate of prior nonresponders was significantly lower than that of relapsers (43.3\% vs 95.9\%) in the Japanese trial of simeprevir based triple therapy for treatment-experienced HCV genotype 1-infeted patients (CONCERTO-2 and CONCERTO-3). ${ }^{23}$ Reddy et al. ${ }^{24}$ also reported that the SVR rate of prior non-responders was low (54\%). In addition, it is reported that the SVR rate of simeprevir based therapy for patients with prior telaprevir failure was 50\%. ${ }^{25}$ In the present study, although SVR rates of treatment naïve and prior relapser were almost equivalent (67\% vs 72\%), that of prior nonresponders was lower (48\%). Therefore, patients with prior nonresponse to PEG-IFN and ribavirin or prior telaprevir failure would not be good candidates for simeprevir based triple therapy.

When the pretreatment factors between SVR and non-SVR groups in the present study were compared, significant differences were noted in IL28B polymorphism and levels of $\gamma$-GT and AFP. Among these significant factors, IL28B polymorphism was the only independent factor. These findings were consistent with those of postmarketing studies in Japan. ${ }^{26,27}$ We also investigated whether super rapid viral response within 2 weeks contributed to SVR. Comparing on-treatment factors between SVR and non-SVR groups, significant differences were noted in the HCV-RNA responses at week 2 and 4 after the start of therapy. However, there was no significant difference in HCV core antigen response. Our previous reports of low dose PEG-IFN and ribavirin therapy for IFN ineligible patients demonstrated that both viral responses of HCV-RNA and HCV core antigen within 2 weeks were useful predictors of SVR. ${ }^{8,9} \mathrm{HCV}$ core antigen is better than HCV-RNA level in terms of low cost, convenience, and rapid results. ${ }^{28}$ However, the response of HCV core antigen was not a useful predictor of SVR in this study. The same finding was shown in our report of telaprevir based triple therapy. ${ }^{11}$ This may be attributed to nonstructural 3/4A protease inhibitors strongly inhibiting HCV-RNA replication. In the present study, on-treatment factors were not independent on multivariate analysis. When the predictability for SVR was compared between IL28B polymorphism and viral response at week 4, the accuracies were also equivalent. Therefore, it could be considered that IL28B polymorphism would be a more useful predictor in deciding the treatment strategy than HCV-RNA response at week 4.

In conclusion, simeprevir-based triple therapy with reduced doses of PEG-IFN and ribavirin was a safe and effective treatment for IFN ineligible patients infected with genotype $1 \mathrm{~b} \mathrm{HCV}$, and IL28B polymorphism would be a useful predictor of SVR. Currently, IFN and ribavirin free treatments using combination of direct acting antiviral agents are the first line treatments for IFN ineligible patients infected with genotype-1b HCV. In the future, the use of simeprevir-based triple therapy with low-dose PEG-IFN plus ribavirin regimen could be considered a safe and cost-effective treatment option for elderly and/or cirrhotic patients with prior sofosbuvir and ledipasvir failure.

\section{CONFLICTS OF INTEREST}

No potential conflict of interest relevant to this article was reported.

\section{REFERENCES}

1. Asahina Y, Tsuchiya K, Tamaki N, et al. Effect of aging on risk for 
hepatocellular carcinoma in chronic hepatitis C virus infection. Hepatology 2010;52:518-527.

2. Editors of the Drafting Committee for Hepatitis Management Guidelines: the Japan Society of Hepatology. Guidelines for the management of hepatitis c virus infection: first edition, May 2012, The Japan Society of Hepatology. Hepatol Res 2013;43:1-34.

3. Huang CF, Yang JF, Dai CY, et al. Efficacy and safety of pegylated interferon combined with ribavirin for the treatment of older patients with chronic hepatitis C. J Infect Dis 2010;201:751-759.

4. Bota S, Sporea I, Sirli R, et al. Severe adverse events during antiviral therapy in hepatitis $\mathrm{C}$ virus cirrhotic patients: a systematic review. World J Hepatol 2013;5:120-126.

5. Di Marco V, Almasio PL, Ferraro D, et al. Peg-interferon alone or combined with ribavirin in HCV cirrhosis with portal hypertension: a randomized controlled trial. J Hepatol 2007;47:484-491.

6. Bruno S, Shiffman ML, Roberts SK, et al. Efficacy and safety of peginterferon alfa-2a (40KD) plus ribavirin in hepatitis $\mathrm{C}$ patients with advanced fibrosis and cirrhosis. Hepatology 2010;51:388397.

7. Roffi L, Colloredo G, Pioltelli P, et al. Pegylated interferon-alpha2b plus ribavirin: an efficacious and well-tolerated treatment regimen for patients with hepatitis $C$ virus related histologically proven cirrhosis. Antivir Ther 2008;13:663-673.

8. Tamai H, Shingaki N, Shiraki T, et al. Prediction of sustained response to low-dose pegylated interferon alpha- $2 \mathrm{~b}$ plus ribavirin in patients with genotype $1 \mathrm{~b}$ and high hepatitis $\mathrm{C}$ virus level using viral reduction within 2 weeks after therapy initiation. Hepatol Res 2011;41:1137-1144.

9. Tamai H, Mori Y, Shingaki N, et al. Low-dose pegylated interferon-alpha2a plus ribavirin therapy for elderly and/or cirrhotic patients with HCV genotype-1b and high viral load. Antivir Ther 2014;19:107-115.

10. Kumada H, Toyota J, Okanoue T, Chayama K, Tsubouchi H, Hayashi N. Telaprevir with peginterferon and ribavirin for treatment-naive patients chronically infected with HCV of genotype 1 in Japan. J Hepatol 2012;56:78-84.

11. Tamai H, Shimizu R, Shingaki N, et al. Prediction of sustained virological response to telaprevir-based triple therapy using viral response within 2 weeks. Hepat Res Treat 2014;2014:748935.

12. Fried MW, Buti M, Dore GJ, et al. Once-daily simeprevir (TMC435) with pegylated interferon and ribavirin in treatment-naïve genotype 1 hepatitis C: the randomized PILLAR study. Hepatology 2013;58:1918-1929.

13. Jacobson IM, Dore GJ, Foster GR, et al. Simeprevir with pegylated interferon alfa 2a plus ribavirin in treatment-naive patients with chronic hepatitis C virus genotype 1 infection (QUEST-1): a phase 3, randomised, double-blind, placebo-controlled trial. Lancet 2014;384:403-413.

14. Manns M, Marcellin P, Poordad F, et al. Simeprevir with pegylated interferon alfa $2 \mathrm{a}$ or $2 \mathrm{~b}$ plus ribavirin in treatment-naive patients with chronic hepatitis C virus genotype 1 infection (QUEST-2): a randomised, double-blind, placebo-controlled phase 3 trial. Lancet 2014;384:414-426.

15. Hayashi N, Izumi N, Kumada H, et al. Simeprevir with peginterferon/ribavirin for treatment-naive hepatitis $\mathrm{C}$ genotype 1 patients in Japan: CONCERTO-1, a phase III trial. J Hepatol 2014;61:219227.

16. Simmonds P, Holmes EC, Cha TA, et al. Classification of hepatitis $\mathrm{C}$ virus into six major genotypes and a series of subtypes by phylogenetic analysis of the NS-5 region. J Gen Virol 1993;74(Pt 11):2391-2399.

17. Enomoto N, Sakuma I, Asahina Y, et al. Mutations in the nonstructural protein $5 \mathrm{~A}$ gene and response to interferon in patients with chronic hepatitis C virus 1b infection. N Engl J Med 1996; 334:77-81.

18. Akuta N, Suzuki F, Sezaki H, et al. Association of amino acid substitution pattern in core protein of hepatitis $\mathrm{C}$ virus genotype $1 \mathrm{~b}$ high viral load and non-virological response to interferonribavirin combination therapy. Intervirology 2005;48:372-380.

19. Tanaka Y, Nishida N, Sugiyama M, et al. Genome-wide association of IL28B with response to pegylated interferon-alpha and ribavirin therapy for chronic hepatitis C. Nat Genet 2009;41:11051109.

20. Roomer R, Hansen BE, Janssen HL, de Knegt RJ. Risk factors for infection during treatment with peginterferon alfa and ribavirin for chronic hepatitis C. Hepatology 2010;52:1225-1231.

21. Ogawa E, Furusyo N, Kajiwara E, et al. Comparative effectiveness and safety study of triple therapy with simeprevir or telaprevir for non-cirrhotic patients with chronic hepatitis $\mathrm{C}$ virus genotype $1 \mathrm{~b}$ infection. J Gastroenterol Hepatol 2015;30:1759-1767.

22. Tahata Y, Hiramatsu N, Oze T, et al. Impact of ribavirin dosage in chronic hepatitis $\mathrm{C}$ patients treated with simeprevir, pegylated interferon plus ribavirin combination therapy. J Med Virol 2016;88:1776-1784.

23. Izumi N, Hayashi N, Kumada H, et al. Once-daily simeprevir with peginterferon and ribavirin for treatment-experienced HCV genotype 1-infected patients in Japan: the CONCERTO-2 and CONCERTO-3 studies. J Gastroenterol 2014;49:941-953.

24. Reddy KR, Zeuzem S, Zoulim F, et al. Simeprevir versus telaprevir with peginterferon and ribavirin in previous null or partial responders with chronic hepatitis C virus genotype 1 infection (ATTAIN): a randomised, double-blind, non-inferiority phase 3 trial. Lancet Infect Dis 2015;15:27-35.

25. Ogawa E, Furusyo N, Dohmen K, et al. Effectiveness of triple therapy with simeprevir for chronic hepatitis $\mathrm{C}$ genotype $1 \mathrm{~b}$ patients with prior telaprevir failure. J Viral Hepat 2015;22:992-1001.

26. Ogawa E, Furusyo N, Kajiwara E, et al. Comparative safety study on severe anemia by simeprevir versus telaprevir-based triple therapy for chronic hepatitis C. J Gastroenterol Hepatol 2015;30:13091316.

27. Tahata Y, Hiramatsu N, Oze T, et al. The impact of an inosine triphosphate pyrophosphatase genotype on bilirubin increase in 
558 Gut and Liver, Vol. 11, No. 4, July 2017

chronic hepatitis C patients treated with simeprevir, pegylated interferon plus ribavirin. J Gastroenterol 2016;51:252-259.

28. Hayashi K, Hasuike S, Kusumoto K, et al. Usefulness of a new immuno-radiometric assay to detect hepatitis C core antigen in a community-based population. J Viral Hepat 2005;12:106-110. 